\title{
Research Paper: Psychometric Properties of the Persian Version of Readiness for Events With Psychological crossuark Emergencies Assessment Tool
}

\author{
Elham Sepahvand ${ }^{1}$, Hamid Reza Khankeh ${ }^{2 *}$, Abas Ebadi
}

1. Department of Nursing, University of Social Welfare and Rehabilitation Sciences, Tehran, Iran.

2. Research Center in Emergency and Disaster Health, University of Social Welfare and Rehabilitation Sciences, Tehran, Iran

3. Department of Nursing, School of Nursing, Baqiyatallah University of Medical Sciences, Tehran, Iran.

$\begin{gathered}\text { Use yur devic to scan } \\ \text { and read the article online }\end{gathered}$
Psychological Emergencies Assessment Tool. Health in Emergencies and Disasters Quarterly. 2017; 2(4):207-216.
dol: ???

Article info:

Received: 28 Dec. 2016

Accepted: 15 Apr. 2017

\section{Keywords:}

Validation, Disasters, Hospitals, Reliability

\begin{abstract}
A B STRACT
Background: In the case of a disastrous event, stress and anxiety often result in psychological diseases such as depression and post-traumatic stress disorder. Health care providers even suffer from such disaster-related disorders. Psychological complications can negatively influence their ability in providing care. Thus, this study aimed to examine the reliability and validity of the Persian version of Readiness for Events with Psychological Emergencies Assessment Tool (REPEAT)
\end{abstract}

Materials and Methods: This cross-sectional study was designed to validate the Persian version of REPEAT. Data were gathered from 140 managers and staff members of select university hospitals in Tehran, Lorestan, and Semnan Provinces through convenient sampling. They were invited to complete REPEAT, which comprised 7 dimensions and 28 statements. Then, the qualitative content, construct validity, and reliability were determined.

Results: In exploratory factor analysis, seven factors (including internal organizational structure and chain of command, resources and infrastructure, knowledge and skills, coordination with external organizations, risk assessment and monitoring, psychological support, and communication and information sharing) were extracted. The following eigenvalues were recorded for these seven factors: $3.59,3.41,2.78,2.61,2.94,2.40$, and 1.39, respectively. The results of Cronbach's alpha showed that the internal consistency of the Persian version of REPEAT was 0.805 . The intraclass correlation coefficient was found to be 0.809 (CI95: 0.501-0.903, $\mathrm{P}<0.001)$.

Conclusion: The results of data analysis revealed that this instrument is highly reliable and valid and can be used as an appropriate tool to measure psychological preparedness of hospitals. However, further validation is needed.

\section{* Corresponding Author:




\section{Introduction}

$\mathbf{D}$

isasters cause severe environmental and socio-psychological chaos. When struck by a disaster, the society usually fails to cope with it, which leads to life and financial damages and spread of related diseases [1].

In recent years, statistics collected from different parts of the world indicate that natural and manmade disasters have been increased; every year, 75000 people die because of unpredictable disasters, which directly affect another 210 million people [2].

Disasters result in the disruption of social systems and affect every aspect of humans' lives. They also cause stress and anxiety, sleep disorder, and disruption in access to care. Every event further leads to major physical and psychological complications. A considerable proportion of these complications take place in the sociopsychological dimension, resulting in psychological diseases $[3,4]$. In the US, researchers concentrated more on the disaster-related psychological complications after the 9/11 terrorist attacks (occurring in 2001) and the Hurricane Katrina (blowing up in 2005). Research findings support the idea that psychological complications arising due to disasters are potentially more important than the physical ones [5].

In the case of a sudden and destructive event, over $25 \%$ of the involved people suffer from symptoms such as consternation, daze, and acute psychological and emotional reactions that may remain for a long time. Additionally, $11 \%$ to $40 \%$ of people experiencing unpredictable disasters may suffer from stress and anxiety, which often result in psychological diseases such as depression and post-traumatic stress disorder [4]. It should be noted that even the health care providers suffer from disasterrelated disorders. Psychological complications can negatively influence their ability in providing care. Therefore, many researchers argue that psychological health should be taken into account in disaster preparedness planning. This will help a wide range of health-related professionals to predict and moderate the psychological consequences of disasters $[5,6]$.

Bishop and Thornby demonstrated that psychological consultation plays an important role in providing services for disaster survivors [7]. The importance of psychological and behavioral health is also displayed by the US federal government, which tries to prepare itself for appropriate response to disasters [8]. Pfefferbaum also indicated that the integration of psychological and behavioral health is necessary to provide suitable services to victims of disasters [9]. Appropriate planning and management in disasters can contribute to better control over conditions and reduce losses. Health centers play a significant role in controlling and planning for disasters [10].

Rescuers and health care providers are the ones who should decide how to provide suitable care for victims [11]. In order to manage natural and man made disasters appropriately, health care systems should make themselves more prepared and constantly try to increase their capabilities [12]. On being psychologically prepared, the health care providers will provide better services in the case of disasters. Providing timely behavioral and psychological interventions can enhance response effectiveness, prevent secondary effects stemming from ineffective responses, improve victims' health condition, and increase people's trust in the government [9].

In recent years, the US has made various attempts to improve healthcare infrastructures and ensure their effectiveness and efficiency. Nonetheless, there are still a number of shortcomings in providing effective responses to psychological effects of disasters [9]. Designing an appropriate instrument to assess the psychological preparedness of hospitals can considerably eliminate many of these shortcomings. There is some information on how hospitals and healthcare clinics deal with disasters; however, there are scare data on how they manage disasterrelated psychological issues. Moreover, despite cognitive development and the need to respond to large-scale disasters, psychological consequences of these disasters have not received due attention. A retrospective consideration of previous events and disasters indicates that the number of people searching for psychological support is 4 to 50 times greater than the number of individuals who look for help to address their physical problems [13-15].

Thus, hospitals and clinics are in great need of an instrument that can help them become more prepared to deal with individuals who demand psychological and emotional support and experience burnout as a result of the struck disaster [16]. Meredith et al. constructed a practical instrument to help hospitals and clinics come up with better plans to respond to psychological problems of people involved in disasters [17]. The use of this instrument can expand hospitals' knowledge base on how to provide better facilities and address demands in the time of disaster. The instrument can also be utilized to gather data periodically to evaluate healthcare centers' preparedness and progress to deal with disasters [17].

This instrument specifies three structural components (internal organizational structure and chain of command, 
resources and infrastructure, and knowledge and skills) and four process components (coordination with external organizations, risk assessment and monitoring, psychological support and intervention, and communication and information sharing). The structural components entail all resources, skills, and elements that are necessary to have an effective psychological response. On the other hand, the process components are associated with evidence-based information and activities that can be applied to better manage the psychological status of involved people (victims, families, and personnel).

Finally, the consequence refers to hospitals' appropriate psychological responses to disasters. Addressing demands in these three areas can improve the effectiveness of hospitals' response to disasters [16]. A review of the available studies shows that little attention has been paid to psychological preparedness for disasters $[18,19]$. It is important to focus on the psychological dimension of disasters and become well prepared to deal with this aspect. Moreover, no instrument has been developed in Iran to measure healthcare centers' preparedness to deal with such disaster-related psychological issues. In addition, the Persian version of Meredith et al.'s instrument has not been validated within Iran. Thus, this study aimed to examine the reliability and validity of the Persian version of Readiness for Events with Psychological Emergencies Assessment Tool (REPEAT).

\section{Materials and Methods}

This cross-sectional study was designed to validate REPEAT. In order to evaluate construct validity, factor analysis was performed; it was found that data must be collected from 5 to 10 participants for each item of the questionnaire [20]. Therefore, data were gathered from 140 managers and staff members of select university hospitals in Tehran, Lorestan, and Semnan Provinces through convenient sampling. They were invited to complete REPEAT, which comprised of 7 dimensions and 28 statements. The components included internal organizational structure and chain of command, resources and infrastructure, knowledge and skills, coordination with external organizations, risk assessment and monitoring, psychological support and intervention, and communication and information.

Each dimension will receive a score of 2 for complete implementation, 1 for relative implementation, and 0 for no implementation in hospital [21]. At first, the questionnaire was retrieved and permission for using it in Iran was sought from Professor Meredith, the developer of the tool. Then, it was translated to Persian using the forward-backward translation approach. Briefly, two individuals who were native in English were requested to translate the instrument into Persian. One of the translators was an expert in medical science terminologies and concepts related to psychological preparedness. The second person, however, was a professional translator and did not have any familiarity with medical science terms and available concepts.

The two translators were asked to convert the instrument from English to Persian independently. After that, the two translated versions were reviewed with special focus on the used equivalents for special terminologies. Then an initial draft of the Persian version of the questionnaire was finalized. This version was subsequently converted into English through back translation and emailed to Professor Meredith for final approval. Professor Meredith kindly reviewed the back-translated instrument and confirmed that it was similar to the original version. To evaluate the validity of the instrument, quality-content validity and construct validity were employed in the next stage.

For determining the qualitative validity of the questionnaire, 10 managers and university faculty members who were health experts in emergency and disaster were invited to review the instrument and give comments on its legibility, clarity, statements' writing style, easy understanding, difficulty level of statements, confusing words, clarity of statements, appropriateness of the classification of responses, ease of responding to the questionnaire, grammatical issues, and spelling [22].

In the third stage, exploratory factor analysis (EFA) was exploited to extract latent variables. Kaiser-MeyerOlkin (KMO, which is a test of sample adequacy) and Bartlett's test were conducted. KMO values of 0.7 to 0.8 are regarded as good while values of 0.8 to 0.9 are considered as excellent [23]. Subsequently, principal component analysis with varimax rotation was carried out to extract the latent variables. SPSS (Version 22) was also used to draw the scree plot. According to statistical rules, factor loadings greater than 0.4 are considered to be significant. Thus, in order to include a statement within a factor, its factor loading should be above 0.4. Moreover, based on the three indicator rule of EFA, there should be at least three observed variables (items) for each latent variable [24]. Communalities of less than 0.5 were removed from EFA [25].

Cronbach's alpha was employed to evaluate the internal consistency of the Persian version of REPEAT. Indices greater than 0.7 showed high internal consistency [26]. 
Furthermore, intraclass correlation coefficient (ICC) was used to calculate consistency over time (i.e., test-retest reliability). Values greater than 0.75 showed appropriate reliability [27]. ICC was estimated using two-way mixed effects and confidence interval of $95 \%$.

For data collection, introduction letters were initially issued by universities and hospitals (i.e., Rasool Akram Hospital in Tehran, Shohada Ashayer Hospital in Khoramabad, and Kosar Hospital in Semnan). The letters were presented to the Chief of Staff, who submitted the list of managers, matrons, and head nurses to the researchers. Invitations were sent to these stakeholders. In several meetings, explanations were provided about the objectives and different stages of the study. Then, written informed consent was received from individuals who were willing to participate in the study. After that, the questionnaire was administered.

\section{Results}

The qualitative validity was confirmed when the instrument was revised based on the content and structure comments received from managers and disaster experts. KMO was found to be 0.718 and $\mathrm{P}<0.001$ (Table 1). In EFA, seven factors (including internal organizational structure and chain of command, resources and infrastructure, knowledge and skills, coordination with external organizations, risk assessment and monitoring, psychological support, and communication and information sharing) were extracted. The following eigenvalues were, respectively, recorded for these seven factors: $3.59,3.41,2.78,2.61,2.94,2.40$, and 1.39. In total, the seven factors explained $66.62 \%$ of the entire variance in the instrument of psychological preparedness of hospitals (Table 2). The results of Cronbach's alpha showed that the internal consistency of the Persian version of REPEAT was 0.805 . The ICC was also found to be 0.809 (CI95: 0.501-0.903, $\mathrm{P}<0.001$ ). The results of Pearson correlation coefficients between the total score and each of the instrument components are illustrated in Table 3.

\section{Discussion}

Psychological preparedness is essential for all individuals who experience burnout as a result of disasters. It is even more crucial for healthcare personnel who might be affected by the psychological complications of disasters. In such a situation, the quality of the health care will be negatively affected. The present study aimed at validating the Persian version of REPEAT. For this, seven factors were extracted from this instrument; these factors explained $66.62 \%$ of the total variance. This finding is in line with the statistical analyses reported by the developers of the original instrument. The Cronbach's alpha index for the whole instrument was 0.805 , and for each component, the value was greater than 0.60 . Face, content, and construct validity of the instrument was approved. Moreover, there was a high internal consistency among items.

The first dimension, internal organizational structure and chain of command, comprised 5 items with an average factor loading of 0.7. When a disaster strikes, managers need to make quick decisions based on the principles of scientific management and their experience. In the time of disasters, individuals need health services, and organizations responsible for providing such services need effective and efficient management to coordinate and organize services [28]. In an attempt to validate an instrument measuring the performance of disaster operations command centers, Vaziri et al. argued that a skillful management system and smooth cooperation among various departments will facilitate effective and timely actions in crisis management while disaster strikes [29].

The second dimension was resources and infrastructure. Resources may entail sufficient number of personnel, capability of providing help, and appropriate space for screening people who are at the risk of psychological emotions [21]. In this component, the three items related to the availability of an agreement for providing psychological health services, availability of adequate medical health staffing and resources for providing psychological health services, and availability of the resource list had

Table 1. KMO and Bartlett's test of sampling adequacy

\begin{tabular}{cc}
\hline KMO & 0.718 \\
\hline Bartlett's Test of Sphericity / Approx Chi-Square & 2086.647 \\
\hline df & 378 \\
\hline Sig. & 0.000 \\
\hline & $\begin{array}{l}\text { |lleatth in } \\
\text { Emergencies and [D]isasters [Oluarterly }\end{array}$ \\
\hline
\end{tabular}


Table 2. Results of Varimax component matrix

\begin{tabular}{|c|c|c|c|c|c|c|c|}
\hline \multirow{2}{*}{ Question Number } & \multicolumn{7}{|c|}{ Component } \\
\hline & 1 & 2 & 3 & 4 & 5 & 6 & 7 \\
\hline 1 & 0.741 & & & & & & \\
\hline 2 & 0.822 & & & & & & \\
\hline 3 & 0.507 & & & & & & \\
\hline 4 & 0.609 & & & & & & \\
\hline 5 & 0.600 & & & & & & \\
\hline 6 & & 0.824 & & & & & \\
\hline 7 & & 0.813 & & & & & \\
\hline 8 & & 0.436 & & & & & \\
\hline 9 & & & & & & 0.556 & \\
\hline 10 & & & 0.458 & & & & \\
\hline 11 & & & 0.825 & & & & \\
\hline 12 & & & 0.848 & & & & \\
\hline 13 & & & 0.469 & & & & \\
\hline 14 & & & 0.706 & & & & \\
\hline 15 & & & 0.820 & & & & \\
\hline 16 & & & & 0.589 & & 0.571 & \\
\hline 17 & & & & 0.683 & & & \\
\hline 18 & & & & 0.677 & & & \\
\hline 19 & & & & 0.773 & & & \\
\hline 20 & & & & & 0.798 & & \\
\hline 21 & & & & & 0.454 & & \\
\hline 22 & & & & & 0.557 & & \\
\hline 23 & & & & & & 0.785 & \\
\hline 24 & & & & & & 0.729 & \\
\hline 25 & & & & & & 0.601 & \\
\hline 26 & 0.459 & & & & & & 0.47 \\
\hline 27 & & & & & & & 0.55 \\
\hline 28 & & & & & & & 0.50 \\
\hline
\end{tabular}


Table 3. Internal consistency (Cronbach's Alpha) and Intra-Class correlation coefficients

\begin{tabular}{|c|c|c|c|c|c|c|c|c|c|c|}
\hline \multirow{2}{*}{ Components } & \multirow{2}{*}{$\begin{array}{l}\text { Items } \\
\text { Number }\end{array}$} & \multirow{2}{*}{ \%Variance } & \multirow{2}{*}{$\begin{array}{l}\text { Eigen } \\
\text { Value }\end{array}$} & \multirow{2}{*}{$\begin{array}{l}\text { Cronbach's } \\
\text { Alpha }\end{array}$} & \multirow{2}{*}{ ICC } & \multicolumn{2}{|c|}{$\mathrm{Cl}=0.95$} & \multirow{2}{*}{$\mathbf{P}$} & \multirow{2}{*}{$\begin{array}{l}\text { Pierson } \\
\text { Correla- } \\
\text { tion Coef- } \\
\text { ficient }\end{array}$} & \multirow{2}{*}{$\mathbf{P}$} \\
\hline & & & & & & MAX & MIN & & & \\
\hline $\begin{array}{l}\text { Internal organi- } \\
\text { zational struc- } \\
\text { ture and chain } \\
\text { of command }\end{array}$ & 5 & 12.82 & 3.59 & 0.757 & 0.751 & 0.835 & 0.254 & 0.004 & 0.672 & 0.000 \\
\hline $\begin{array}{l}\text { Resources and } \\
\text { infrastructure }\end{array}$ & 3 & 12.17 & 3.41 & 0.712 & 0.775 & 0.903 & 0.433 & 0.000 & 0.697 & 0.000 \\
\hline $\begin{array}{l}\text { Knowledge and } \\
\text { skills }\end{array}$ & 6 & 9.94 & 2.87 & 0.762 & 0.829 & 0.930 & 0.506 & 0.000 & 0.653 & 0.000 \\
\hline $\begin{array}{l}\text { Coordination } \\
\text { with external } \\
\text { organizations }\end{array}$ & 3 & 9.35 & 2.61 & 0.636 & 0.641 & 0.771 & 0.066 & 0.036 & 0.696 & 0.000 \\
\hline $\begin{array}{l}\text { Risk assessment } \\
\text { and monitoring }\end{array}$ & 4 & 8.73 & 2.44 & 0.800 & 0.790 & 0.902 & 0.549 & 0.000 & 0.742 & 0.000 \\
\hline $\begin{array}{l}\text { Psychological } \\
\text { support and } \\
\text { intervention }\end{array}$ & 3 & 8.59 & 2.40 & 0.671 & 0.797 & 0.905 & 0.564 & 0.000 & 0.601 & 0.001 \\
\hline $\begin{array}{l}\text { Communication } \\
\text { and information } \\
\text { sharing }\end{array}$ & 3 & 4.99 & 1.39 & 0.715 & 0.764 & 0.784 & 0.067 & 0.008 & 0.319 & 0.092 \\
\hline Total & 28 & 66.62 & - & 0.898 & 0.881 & 0.903 & 0.591 & 0.000 & 1 & 0.000 \\
\hline
\end{tabular}

factor loadings of $0.846,0.813$, and 0.436 , respectively. Nevertheless, the item that had to do with the availability of enough resources for increasing number of affected people was removed because of its low factor loading. It may be argued that this item was embedded within another item (i.e. availability of resources). One of the essential elements of planning for disaster preparedness is the availability of trained staff members who are well aware of their responsibilities and know how to protect themselves and provide help to survivors [21].

The third dimension, knowledge and skills, consisted of 6 items with high Cronbach's alpha index and ICC. The items in this dimension are related to designing and implementing training programs on how to deal with disaster-related risks and provide psychological interventions for victims. High factor loading of this component shows the necessity of training staff members on psychological preparedness. According to the American Psychological Association statement, all healthcare personnel should be familiar with unique patterns of psychological response to victims affected by disasters. Ad- ditionally, the American Medical Institute recently stated that a wide range of healthcare providers should become familiar with disaster-related psychological needs [6].

The fourth dimension of the instrument entails coordination with external organizations. The factor loading of this component was around 0.6 , which is a relatively low value. This might be attributed to the lack of emphasis on this area in discussions related to the psychological preparedness of hospitals for disasters. With respect to this component, domain experts have claimed that both private and public sectors in Iran suffer from lack of coordination and necessary protocols among emergency teams. They have also argued that not many management decisions and planning attempts are based on accurate information $[19,30]$. In his study, Walsh reported that in order to enhance hospitals' preparedness to deal with disasters, coordination among healthcare systems should be promoted, opportunities for raising the efficiency of the system should be identified, and coordination among responsible organizations and hospitals should be improved [31]. 
The fifth dimension was risk assessment and monitoring. One of the items in this component (i.e., designing screening and risk assessment protocols) had a factor loading of 0.7 while the second item (i.e., risk monitoring tools for assessing psychological needs and staff's familiarity with them) had a factor loading of 0.5 . Identifying and providing timely interventions can eliminate mental health problems when disaster strikes, reduce negative psychological effects of the disaster, and enhance the quality of provided care. According to the United States Department of Health and Human Resources, risk assessment makes it possible for health providers to appropriately identify severe psychological problems among disaster survivors [32].

The risk assessment instrument helps care givers identify disaster-related psychological disorders promptly and treat them as soon as possible. Existing evidence indicates that healthcare providers should to be trained on how to use the risk assessment tool [33]. One of the tools in this regard is the Risk Assessment Index, which is a quick tool for screening and assessing preparedness [29]. However, this tool does not specifically assess the risk of psychological disorders after a disaster. Furthermore, the low factor loading of the item related to the procedure for using the tool may indicate that hospitals do not use this tool to assess risks. It is, therefore, essential to hold workshops in which healthcare providers receive appropriate training on how to use the risk assessment tool.

The sixth component is psychological support and intervention during a disaster. The factor loading of this component was rather high (0.7). Rabiee listed some of the psychological interventions that may be provided as a result of a disaster. These interventions encompass preparedness before the disaster, psychological first aid for survivors, verbal interventions, social support for individuals and groups, collection of enough information, and consideration of individuals' cultural differences [34]. Investigation of the managers' viewpoints showed that despite the importance of providing psychological support for disaster survivors, it has received less attention compared to their physical needs and shelter provision. Moreover, lack of knowledge about psychological interventions leads to psychological problems among survivors and healthcare providers [34].

The seventh component of the instrument is related to communication and information sharing. It comprised three items entailing medical health staff's contribution to communicating risks, dissemination of understandable messages, and availability of preplanned risk communication messages. High factor loading of this com- ponent indicates the significant role of communication in reducing negative effects of disaster-related psychological anxiety. Related studies have showed that enhancing team work among healthcare providers significantly improves the services they provide, especially in stressful situations [28].

Effective team work and communication are crucial for achieving organized responses; therefore, the team behavior of healthcare staff should be evaluated to come up with a comprehensive assessment of hospital's preparedness in dealing with calamities. Evaluating team behavior includes assessing the team's communication in sharing information, the team's capability in monitoring and reviewing their performance, and improvement of processes in the team [1]. Kaji also highlighted the importance of having a tool to assess the psychological preparedness of hospitals during disasters [35].

\section{Conclusion}

The present study aimed at examining the reliability and validity of the Persian version of Readiness for Events with Psychological Emergencies Assessment Tool. The results of data analysis revealed that this instrument is highly reliable and valid and can be used as an appropriate tool to measure psychological preparedness of hospitals. Low factor loading of some items in this instrument indicates that further studies are required to improve the constituent statements. Also, more studies are needed to discover how psychological preparedness of hospitals can be improved to reduce the negative consequences of emotional stress in dealing with disasters and minimize psychological disorders such as posttraumatic stress disorder.

\section{Acknowledgments}

We express our sincere gratitude towards professors and Deputy Management of the University of Social Welfare and Rehabilitation Sciences for their cooperation in the research project. This project submitted with 96/801/ت/6416 code.

\section{Conflict of Interest}

The authors declared no conflicts of interest. 


\section{References}

[1] World Health Organization. Mental health in emergencies: Mental and social aspects of health of populations exposed to extreme stressors. Geneva: World Health Organization; 2003.

[2] Al Khalaileh MA, Bond E, Alasad JA. Jordanian nurses' perceptions of their preparedness for disaster management. International Emergency Nursing. 2012; 20(1):14-23. doi: 10.1016/j.ienj.2011.01.001

[3] McFarlane AC, Williams R. Mental health services required after disasters: Learning from the lasting effects of disasters. Depression Research and Treatment. 2012; 2012:1-13. doi: $10.1155 / 2012 / 970194$

[4] Gould DW. Disaster mental health surveillance at state health agencies: Results from a 2013 CSTE Assessment. Paper presented at: The 2014 CSTE Annual Conference. 22-26 June 2014; Nashville, USA.

[5] Ablah E, Hawley S, Konda KM, Wolfe D, Cook DJ. Evaluation of mental health emergency preparedness among health professionals. Journal of Allied Health. 2008; 37(3):144-9. PMID: 18847110

[6] Everly Jr GS, McCabe OL, Semon NL, Thompson CB, Links JM. The development of a model of psychological first aid for non-mental health trained public health personnel: The Johns Hopkins RAPID-PFA. Journal of Public Health Management and Practice. 2014; 20:S24-S9. doi: 10.1097/ phh.0000000000000065

[7] Bishop LC, Thornby J. Psychiatric consultation with medical evacuees of Hurricane Katrina. Wilderness \& Environmental Medicine. 2009; 20(1):1-5.doi: 10.1580/06-weme-or-040.1

[8] McLoughlin D. A framework for integrated emergency management. Public Administration Review. 1985; 45:165-72. doi: $10.2307 / 3135011$

[9] Pfefferbaum B, Flynn BW, Schonfeld D, Brown LM, Jacobs GA, Dodgen D, et al. The integration of mental and behavioral health into disaster preparedness, response, and recovery. Disaster Medicine and Public Health Preparedness. 2012; 6(01):60-6. doi: 10.1001/dmp.2012.1

[10] Daneshmandi M, Nezamzadeh M, Zareiyan A. Assessment the preparedness of selected hospital to deal with disasters in Tehran. Military Caring Sciences. 2014; 1(1):28-35. doi 10.18869/acadpub.mcs.1.1.28

[11] Jennings-Sanders A. Teaching disaster nursing by utilizing the Jennings disaster nursing management model. Nurse Education in Practice. 2004; 4(1):69-76. doi: 10.1016/s14715953(03)00007-6

[12] Spain KM, Clements PT, DeRanieri JT, Holt K. When disaster happens: Emergency preparedness for nurse practitioners. The Journal for Nurse Practitioners. 2012; 8(1):38-44. doi: 10.1016/j.nurpra.2011.07.024

[13] Kawana N, Ishimatsu S, Kanda K. Psycho-physiological effects of the terrorist sarin attack on the Tokyo subway system. Military Medicine. 2001; 166(12):23-6. PMID: 11778423

[14] Stein BD, Tanielian TL, Eisenman DP, Keyser DJ, Burnam MA, Pincus HA. Emotional and behavioral consequences of bioterrorism: Planning a public health response. Milbank Quarterly. 2004; 82(3):413-55. doi: 10.1111/j.0887378x.2004.00317.x
[15] Norris FH, Friedman MJ, Watson PJ, Byrne CM, Diaz E Kaniasty K. 60,000 disaster victims speak: Part I. An empirical review of the empirical literature, 1981-2001. Psychiatry: Interpersonal and Biological Processes. 2002; 65(3):207-39. doi: 10.1521/psyc.65.3.207.20173

[16] Meredith LS, Zazzali JL, Shields S, Eisenman DP, Alsabagh H. Psychological effects of patient surge in large-scale emergencies: a quality improvement tool for hospital and clinic capacity planning and response. Prehospital and Disaster Medicine. 2010; 25(02):107-14. doi: 10.1017/s1049023x00007810

[17] Meredith LS, Eisenman DP, Tanielian T, Taylor SL, Basurto R. Preparing hospitals and clinics for the psychological consequences of a terrorist incident or other public health emergency. Los Angeles: RAND; 2007.

[18] Terhakopian A, Benedek DM. Hospital disaster preparedness: mental and behavioral health interventions for infectious disease outbreaks and bioterrorism incidents. American Journal of Disaster Medicine. 2006; 2(1):43-50. PMID: 18268874

[19] Asefzadeh S, Rajaee R, Ghamari F, Kalhor R, Gholami S. Preparedness of Iranian Hospitals Against Disasters. Biotechnology and Health Sciences. 2016; 3(3):e35073. doi: 10.17795/ bhs-35073

[20] Kellar SP, Kelvin EA. Munro's statistical methods for health care research. Philadelphia: Lippincott Williams \& Wilkins; 2012.

[21] Meredith LS, Eisenman DP, Tanielian T, Taylor SL, Basurto-Davila R, Zazzali J, et al. Prioritizing "psychological" consequences for disaster preparedness and response: a framework for addressing the emotional, behavioral, and cognitive effects of patient surge in large-scale disasters. Disaster Medicine and Public Health Preparedness. 2011; 5(01):73-80. doi: 10.1001/dmp.2010.47

[22] World Health Organization. Process of translation and adaptation of instruments. Geneva: World Health Organization; 2009.

[23] Sharif Nia H, Ebadi A, Lehto RH, Mousavi B, Peyrovi H, Chan YH. Reliability and validity of the Persian version of templer death anxiety scale- extended in veterans of Iran-Iraq qarfare. Iranian Journal of Psychiatry and Behavioral Sciences. 2014; 8(4):29-37. PMCID: PMC4364474

[24] Munro BH. Statistical methods for health care research. Philadelphia: Lippincott Williams \& Wilkins; 2005.

[25] Samitsch C. Data quality and its impacts on decisionmaking: How managers can benefit from good data. Berlin: Springer; 2014.

[26] Mayers A. Introduction to statistics and SPSS in psychology. London: Pearson Education; 2013.

[27] Shoukri MM. Measures of Interobserver Agreement and Reliability: CRC Press; 2011

[28] Delshad V, Borhani F, Khankeh H, Abbaszadeh A, Sabzalizadeh S, Moradian MJ, et al. The effect of activating early warning system on Motahari hospital preparedness. Health in Emergencies and Disasters. 2015; 1(1):3-8.

[29] Vaziri N, Ardalan A, Rahimi Fa, Ahmadnezhad E. [Designing and determining the validity and reliability of questionnaire of disaster management performance (Persian)]. Journal of Hospital. 2015; 14(1): 63-70 
[30] Farajzadeh H, Partovipoor E, Masori N, Safdari R. [Comparative study of natural disaster health information system in U.S.A, Japan and Iran (Persian)]. Hayat. 2007; 12(4):67-77.

[31] Walsh L, Craddock H, Gulley K, Strauss-Riggs K, Schor KW. Building health care system capacity: Training health care professionals in disaster preparedness health care coalitions. Prehospital and Disaster Medicine. 2015; 30(2):123-30. doi: $10.1017 /$ s1049023x14001460

[32] Federal government of the United States. Mental health response to mass violence and terrorism: A field guide. Washington, D.C.: Federal government of the United States; 2013.

[33] Brannen DE, Barcus R, McDonnell MA, Price A, Alsept C, Caudill K. Mental health triage tools for medically cleared disaster survivors: An evaluation by MRC volunteers and public health workers. Disaster Medicine and Public Health Preparedness. 2013; 7(1):20-8. doi: 10.1001/dmp.2012.49

[34] Rabiei A, Nakhaee N, Pourhosseini SS. Shortcomings in dealing with psychological effects of natural disasters in Iran Iranian Journal of Public Health. 2014; 43(8):1132. PMCID: PMC4411910

[35] Kaji AH, Langford V, Lewis RJ. Assessing hospital disaster preparedness: a comparison of an on-site survey, directly observed drill performance, and video analysis of teamwork. Annals of Emergency Medicine. 2008; 52(3):195-201. doi: 10.1016/j.annemergmed.2007.10.026 
